I. VARIA 


\title{
INCOMPATIBLE ONTOLOGIES IN THE TRANSPOSITION OF GRAPHIC NOVELS TO FILMS
}

\author{
Camila Augusta Pires de Figueiredo \\ Mestre em Letras: Literaturas de Expressão Inglesa / UFMG
}

\begin{abstract}
This article proposes a discussion on the specificities of the comics medium and their consequence to the process of transposition of comics - and particularly of graphic novels - into films. In order to support this debate, I will draw upon Irina Rajewsky’s and Pascal Lefèvre's theoretical articles.
\end{abstract}

KEYWORDS

Graphic novel, intermediality, intermedial transposition, adaptation

For distinct reasons, comics and film adaptations are often seen as inferior forms of representation. In the case of film, especially when is inspired by a novel, the usual commentary is that it is merely a pale version of an "original”. Similarly, comics has for many years been consigned to the strips in newspapers and to children's shelves at libraries and bookstores.

Nevertheless, perhaps because of their public appeal and lack of pretension as art forms, comics and films have always conversed with each other. The influence involved motifs, storyline structure, perspectives and subjects. This relationship is natural because both arts are essentially narrative, constructed under iconic signs.

Even though the relationship between cinema and comics is not a new phenomenon, the recent years have witnessed a considerable rise in the number of films based on comic books, which have been successful, if not for the critics, certainly in the box-office.

This rediscovery of comics as source-texts for profitable films finds two explanations. First, the fact that some comics have "grown up”, bringing the need for a new category in comics genres and new designations, such as the graphic novel. The 
graphic novel may not be confused with a new medium or a (sub)genre of literature. Rather, the graphic novel may be understood as a distinct format within the comics medium, with its own genres and nuances. Two works that can be considered landmarks in the field are Frank Miller's Sin city series (1990s) and Alan Moore's Watchmen (1995). Among other distinguished works, these two are known for having contributed in the delimitation and characterization of the graphic novel category.

The second reason for the recent increase in the number of films based on comics is the development of digital technology in cinema. Particularly in the case of adaptations of comic books, digital technology has redefined the aesthetics of film, causing a necessity to recreate the appearance of the comic book on screen. The influence of the comics medium is not limited to the adaptation of the plot, characters and dialogues, but it also now applies to its look, which is only possible because of advances in film techniques.

Even though "comics cinema" has become a recurrent practice nowadays, the relationship between the two media has been quite overlooked among critics and scholars in the field of adaptation studies. For many years, the subject was restricted to finding filmic equivalents for comics’ specific mediatic qualities and vice-versa. To change this, it is fundamental to recognize comics as an autonomous medium, with mediatic qualities distinct from those of literature. Because of this, my argument is that the transposition of comics to cinema involves more aspects than the existing novel-tofilm adaptations are able to comprise.

First, it must be explained that the object of this analysis belongs to intermedia studies, as it consists in a phenomenon that takes place between two media (as the prefix inter indicates). ${ }^{1}$ According to media theoretician Irina Rajewsky, intermedial practices can be subdivided into three categories: media combination, media transposition and intermedial references. The first sub-category, media combination, examines the intermedial qualities within a specific media product. To Rajewsky, it involves the combination of "at least two conventionally distinct media or medial forms of articulation”2 within a certain text. In the case of this analysis, it provides us with the

1 Cf. with Irina Rajewsky's definition of intermediality. RAJEWSKY. Intermediality, intertextuality, and remediation. A literary perspective on intermediality, p. 46.

2 RAJEWSKY, Intermediality, intertextuality, and remediation. A literary perspective on intermediality, p. 52. 
tools to understand the medial distinctions between a novel and comics and the consequence of that distinction to the process of adaptation to cinema.

Although most cultural products nowadays are composite forms resulting from media combination, ${ }^{3}$ a traditional novel is made up of a single mediatic configuration, which is the verbal one. Comics, on the other hand, "contains complex signs in different media that would not reach coherence or self-sufficiency outside that context". ${ }^{4}$ Indeed, one of the main characteristics of comics is its juxtaposition of the verbal and the visual texts, which can be combined in multiple ways, causing different effects to the narrative. More than the meaning produced by either verbal or visual text considered alone, the juxtaposition of verbal and visual texts in comics offers the reader a third layer of meaning. It is a narrative that can only be perceived if both graphic and textual elements are equally considered. This does not happen in traditional novels and must be taken into account when we analyze adaptations of comics to cinema.

Considered one of the most known processes of media transposition (the second subcategory of intermediality proposed by Rajewsky), film adaptations have conquered an important place in academic debate through the works of George Bluestone, Geoffrey Wagner, Brian McFarlane and Robert Stam, among others. However, with a few exceptions, ${ }^{5}$ the scope of these works has been mostly limited to novel-to-film analyses.

As an attempt to fill this theoretical gap, in "Incompatible visual ontologies? The problematic adaptation of drawn images" Pascal Lefèvre examines the process of adaptation of comics to cinema, pointing out to the elements in each medium that may represent a problem in the director's task of transposition. The innovative quality of Lefèvre's work lays on the fact that, instead of simply finding filmic equivalents for comics and vice-versa, the author proposes an evaluation of the process of transposition, considering the constraints and possibilities of each medium and the consequences of these particularities to the director and the public.

\footnotetext{
${ }^{3}$ Films, for instance, combine coherent separable texts, formed by different media such as music, dance, theater, etc.

${ }^{4}$ CLÜVER. Estudos Interartes: conceitos, termos, objetivos, p. 8.

${ }^{5}$ Such as Cartmell and Whelehan, who deal with source-texts for film adaptation other than literary texts in Adaptations: From text to screen, screen to text.
} 
For Pascal Lefèvre, four main ontological differences between comics and film language devices influence the process of adaptation and tend to make the task of the director of this type of adaptation quite complex.

\section{THE FOUR INCOMPATIBLE ONTOLOGIES}

The first incompatibility Lefèvre mentions is the one between the narrative structure of comics and of films. The narrative of a work always undergoes changes when transposed to cinema and these changes can be additions, condensations and deletions. This is a necessary procedure because every medium offers devices that can be used to tell the story in a particular way. Therefore, the same narrative elements that work in a comic book or a graphic novel may not work in a film. Lefèvre's first category can also be applied to the narrative of a novel, which will always suffer additions and deletions when transposed to a film. The difference is that, in comics, both the text and the drawings represent the totality of the narrative, since images also have a narrative potential. Thus, when comics is transposed to cinema, the director has to adapt its narrative in two levels: text and image.

Furthermore, in some cases, these changes in narrative can be aggravated by the possibilities added by the DVD technology. Today, DVD technology has allowed a reorganization of the movie's narrative, giving access to deleted scenes, supplementary material and to the possibility of selecting "chapters" from the menu, sometimes even separating those which were once intertwined subplots within the movie. For instance, in Watchmen, a 2009 film by Zack Snyder, two subplots that appear intertwined in the main narrative of the graphic novel were provided in an exclusive DVD. Afterwards, these stories were combined with the Director's Cut of the main film and released as Watchmen - the ultimate cut, in an effort to be as closest as possible from the graphic novel or to offer the spectator "The complete experience", as it was advertised in the film's promotional website.

In addition to the possibilities offered by the DVD, today the transposition of the narrative is also complicated by the massive use of other media to complement the movie's narrative, a phenomenon called by Henry Jenkins as transmedia storytelling or transmedia narrative. In fact, more and more often films are becoming franchises, with a main narrative plot - often the movie itself - which is complemented and amplified by means of ancillary tools such as alternate reality games (ARGs), websites and 
videogames. In some extreme cases, only the user/viewer/spectator that has access to exclusive material in these other media is able to have a complete understanding of certain episodes of the film. In Watchmen's adaptation to cinema, transmedia strategies were used to provide all the necessary storylines and details that compose the graphic novel. Additionally, the fan could also access the multiple official websites with games, videos and photos created with the objective of enhancing the verisimilitude of the story and increasing the expectation in relation to the release of the film on theaters.

Although the transmedia phenomenon is not exclusive of "comics cinema", it happens more frequently with this kind of film. This is due to the ability of comics to create fictional worlds which are well-known to a wide public, especially because of their long-running narratives. More frequently than in any other medium, these imaginary worlds are familiar to a large public, who grew up either reading the monthly comics adventures or maybe listening to these stories from their parents. For example, one does not have to be a die-hard comics fan to know that Superman is Clark Kent, an extraterrestrial child who grows up in a farm and later becomes a reporter at the Daily Planet, in Metropolis. These pieces of information are part of a mythology involving the character, which is known even to those who never read a Superman comic book.

The second incompatibility mentioned by Lefèvre is the difference between the layout of the comics page and the layout of the film screen. As Lefèvre observes,

[i]n film the shots are put on a linear-time sequence; in comics the panels are not only placed in a linear sequence but also on a larger space, namely the page. In this sense comics are a more spatial medium than film. ${ }^{6}$

In an attempt to enrich the author's argument, I would like to propose a brief discussion on this incompatibility by examining the layout of the page in Frank Miller's Sin city and the layout of the screen in its film version. First, it is necessary to observe the layout of the pages of the graphic novel. In this moment, it must be detected if the artist follows a specific pattern in the size and disposition of the drawings and panels. In Sin city, the elements that compose the comics page (the panels, the gutters and their disposition on the page), are mostly irregular and ostentatious, calling reader's attention more to the graphic layout than to the textual portion of the page. Panels and strips are not considered fundamental elements of a page; there is a profuse use of full-page and

\footnotetext{
${ }^{6}$ LEFÈVRE. Incompatible visual ontologies? The problematic adaptation of drawn images, p. 5-6.
} 
double-page compositions that can either comply with the white page margin or not and which sometimes dispute reader's attention with other small superimposed panels.

Having reached a conclusion about the page layout in Sin city, we need to observe the usual procedures used in transposing the page to the film screen. While the comics page is generally made up of several panels separated by gutters, the film screen has a standardized format, which is usually filled with one image. ${ }^{7}$ Considering that in cinema the screen layout is regular, the inconstancy of layout in Miller's work may seem at first a huge obstacle for the director. Nevertheless, the abundance of full-page and double-page compositions in Sin city favors its film adaptation, as pages are successfully used as storyboards. In other cases, where multiple small panels are distributed within larger compositions, each panel is generally adapted as one frame of the film.

Again, this second incompatibility is also true in novels. One page of a novel does not correspond to one photogram; the narrative told in a page of a novel page can take several film sequences. The reading of the novel also differs from the speed of film projection. A two-hour film projection can condense several hundred pages of a novel and many hours of reading time. Hence, it is possible to say that Lefèvre's distinction between the page and the film screen layout also applies to the pages of a novel.

The third point mentioned by Lefèvre refers to the sound in film, in contrast with the silence in comics. The sound elements in film may comprise the narration (through both the character's voice and the voice-over) and the soundtrack, which includes ambient noises. In contrast, comics is regarded as a mute medium, in which sound can be expressed - but never heard - through the balloon/text font and the onomatopoeia, a device typical of comics. Once more, Lefèvre's aspect functions for both comics and novels. In novels, sound is not heard, but only represented. It is the reader's task to imagine the sound of the character's voices and of the noises described.

Alan Moore's Watchmen, for instance, does not contain any onomatopoeic sounds but has several references to excerpts of songs, which are used, most of the times, to comment on a certain event of the narrative or to establish mood. However, when transposed to film, some songs were substituted for other songs from the same

7 Unless the director deliberately chooses not to conform to this convention, using unconventional techniques such as the split-screen device. 
time period (the nineteen eighties), ${ }^{8}$ while others were just repositioned within the narrative. These changes established new connections between the songs and the story. They produced a resignification of the narrative of the graphic novel, resulting in original and interesting meanings to the spectator. This is the case of Richard Wagner's The ride of the valkyries and Nat King Cole's Unforgettable.

In the graphic novel, Wagner's classical piece is mentioned in the supplementary material of the first chapter, when character Hollis Mason talks about his personal experiences in the fictional memoir Under the hood: "The saddest thing I can think of is The ride of the valkyries. Every time I hear it I get depressed and start wondering about the lot of humanity and the unfairness of life." ${ }^{9}$ Mason explains that the opera reminds him of the owner of the mechanic shop where his father used to work. The man was listening to it when he discovered his wife had been cheating on him for over two years with one of his employees. He committed suicide on that same day.

In the movie, reference to The ride of valkyries is made in a completely different way. The opera plays during the participation and victory of the United States at the Vietnam War. Curiously, there is a long tradition of using of this classical piece in films accompanying military actions. In D.W. Griffith's The birth of a nation (1915), it was used in a sequence showing the American Civil War and in Bryan Singer's Valkyrie (2008), the Second World War. But, perhaps, the most evident inspiration for the use of Wagner's opera in that particular sequence in Snyder's film is Apocalypse now (1979), by Francis Ford Coppola, in which it is used in a scene where a Vietnamese village is being attacked by helicopters.

Another interesting case is the one of Nat King Cole's well-known song Unforgettable. Although it is used in the film in the same way as in the graphic novel (in the TV commercial of a perfume), it appears in a different position and context inside the film narrative, which confers the song (and the story) a completely different meaning. In the graphic novel, for instance, characters Dan and Laurie are watching a news program on TV when Laurie reveals she feels attracted to him. As she kisses Dan, the song starts playing during the TV commercial for the perfume. At that moment, Unforgettable serves as soundtrack for the almost-consummated love scene that follows. In the film, the song is also played during the commercial for the same

\footnotetext{
${ }^{8}$ This was meant to be consistent with the alternate 1980s, the time when Watchmen's story takes place.

${ }^{9}$ MOORE. Watchmen, p. 29.
} 
perfume, but the episode does not show characters Laurie and Dan. The commercial appears in the first sequence of the movie, as Edward Blake - who used to impersonate the superhero Comedian - watches TV at home, moments before being attacked and killed. In this sense, the romantic song lyrics and the idea of nostalgia is not connected to Laurie and Dan's relationship anymore. Instead, it serves to illustrate Blake’s longing for his glamorous past times as a superhero.

Finally, the fourth aspect is the incompatibility in the transposition of drawings in comics to photography in films. Because both comics and cinema share some formal properties - both tell stories through sequences of images -, there is a belief that adapting comics to cinema is easier than adapting a novel. In fact, as Lefèvre reminds us, it is quite the opposite, given that the visual ontology of a drawing in comics represents a problem for an adaptation to a live-action movie.

Although both use images, the two media have distinct image iconicity: while image in cinema is characterized by the photographic materiality, in comics it is marked by its specific graphism. This means that, among other crucial differences, ${ }^{10}$ while image in film is realistic and "anonymous", image in comics is always "signed" by the artist. When the artist is drawing, s/he unavoidably imprints his/her own graphic style to the drawing, which results in variations on the type of trace, use of color, nuances involving light and shadows and even variations on choices between a more realistic or iconic representation. ${ }^{11}$

Indeed, most of the time, it is true that comics use drawn images and films, photographed ones. However, both media have been deeply affected by the use of digital technology, which brings together drawings in comics to photography in films. The images that result from that intervention have created distinct visual aesthetics for cinema. ${ }^{12}$ This is because, with all the possibilities created by digital technology, some particular characteristics of comics - such as the use of colors, light and shadows, characters' features and other effects - are now reproduced without grotesque or evident traces of image manipulation. In fact, one of the main characteristics of digital

\footnotetext{
${ }^{10}$ For other four differences between the filmic and the comics image, see GROENSTEEN'S. Du $7^{\mathrm{e}}$ au $9^{\mathrm{e}}$ art: l'inventaire des singularités, p. 21-24.

${ }^{11}$ And, because graphic novels are usually drawn by a single artist, they have a stronger "signature". Their graphic style is more easily identifiable and, consequently, the pressure for the film director to capture it and transpose it to cinema seems to be greater.

${ }^{12}$ Although this new visual aesthetics is present not only "comics cinema”, it surely happens more frequently in this case.
} 
technology in cinema is its ability to produce a seamless effect of the digitally manipulated image.

The use of digital technology is particularly interesting in comics-to-film adaptations because it often aims at recreating the aesthetics of the comic book on screen, which characterizes an intermedial reference, the third subcategory of intermediality, as proposed by Irina Rajewsky. ${ }^{13}$ In intermedial references a text of one medium evokes or imitates an individual work produced in another medium, a specific medial subsystem (such as a certain film genre) or generic qualities of another medium. This is an extremely common practice and it can be done for a variety of reasons and objectives. Generally, an intermedial reference is a way to pay homage to a particular work or to create an "illusion-forming quality" inherent to the techniques of a certain medium. It is intertextuality between media.

This reference occurs, for example, in Frank Miller's Sin city series which evokes the aesthetics of the noir film genre, especially because of the strong contrast between light and shadow and the style of narration - first-person monologues with short sentences of strong effect.

But, more than a reference to a quality of a film genre, the film Sin city is a reference to the graphic novel series by Frank Miller. Generally referred to as the most faithful translation of comics to film, one of the most striking characteristics in Sin city is the directors' attempt to closely match the look rather than just the plot of the sourcetext. It is perhaps the first time that the "comic book effect" is successfully achieved by means of digital technology. ${ }^{14}$ And, most importantly, more than an attempt to imitate comics' general characteristics, the film is an attempt to imitate some exclusive features of Frank Miller's graphic novel series. In this sense, the film's photography aims at reproducing the artist's "signature" and view of the world. The result is that the spectator is constantly reminded of the source-text: that what he is watching is not only a film, but the film version of that specific graphic novel.

13 The use of digital technology may serve other purposes such as enhancing the film experience, as in James Cameron's Avatar (2009), or imitating a particular aesthetic style, as in Sky captain and the world of tomorrow (2004), which uses digital technology in order to evoke retro-futurism.

${ }^{14}$ The search for the aesthetics of comic books began some time ago, as works such as Dick Tracy (1990) prove. However, in opposition to Sin city, in Dick Tracy the image is materially altered, especially by means of fabricated props and prosthetic make up. 
The successful visual effect in Sin city is achieved through the use of CGI (computer-generated images) and digital interference on characters. Characters perform in front of a green screen and not photographed landscapes. Later, the CGI is included to compose the final look of the shot. Real locations and sets are replaced by computer designed backgrounds. There are only three real sets on the film.

Digital interference in Sin city also affects characters. In several moments, the colors of eyes and of other compositional details of characters are altered. Most of the time, this happens with the purpose of emphasizing certain parts of the image, conferring on them a thematic connotation within the story. At a certain moment, for instance, a character's glasses have an opaque white color, which contrast with the almost completely dark rest of the image. The purpose is to emphasize his villainy and emotionless character. At other moments, a girl's lips are colored red; this highlights the character's strong sex appeal.

Considering the substantial use of digital compositing and interference in film images in Sin city, it is possible to say that this film does not fit within the photographed nature of the cinematic image. Rather, it seems to belong to a "postphotographic digital ontology” 15 that characterizes contemporary cinema in general. As a matter of fact, we may have come to a moment in which it is not possible to distinguish cinema from other media in terms of its photographic quality. Some films have combined digital technology to the usual filming process in a way that it is hard for the spectator to distinguish "real" from "fabricated" images. In this sense, perhaps the "drawing vs. the photographed" cannot be used anymore as a criterion to distinguish the type of image in comics from the image in films.

Undoubtedly, Pascal Lefèvre’s article is a useful tool to examine comics-to-film adaptations for the reason that it is maybe the only available work that theoretically considers not only the correspondences between the language of the comics and films, but also the issues involving the process of media transposition itself.

Analyzing the four ontological incompatibilities between comics and cinema proposed by Lefèvre, we have observed that the first three (narrative, page layout and sound) can also be applied to the case of novel-to-film adaptations. Therefore, the most relevant distinction between comics and film images is perhaps the nature of the image, generally drawn by the hands of artists in comics and photographed in films. While

\footnotetext{
${ }^{15}$ GRUSIN. DVDs, video games and the cinema of interactions, p. 71.
} 
Lefèvre gets to mention that "[i]n particular, the visual ontology of a drawing seems to be a central issue", ${ }^{16}$ he does not acknowledge the reason why this distinction is central to the study of this kind of adaptation. This identification of pictorial elements of comics as the main aspect differentiating comics-to-film adaptations from novel-to-film ones represents my contribution to Lefèvre's work. However, this ontological incompatibility remains to be further investigated regarding the consequences of the regular use of digital technology in today's cinema.

\section{RESUMO}

Este artigo propõe a discussão sobre as especificidades da mídia dos quadrinhos e as consequências destas para o processo de transposição de quadrinhos - e especialmente de romances gráficos - para o cinema. Como suporte a este debate, serão utilizados os artigos teóricos de Irina Rajewsky e Pascal Lefèvre.

\section{PALAVRAS-CHAVE}

Romance gráfico, intermidialidade, transposição intermidiática, adaptação

\section{REFERENCES}

CARTMELL, Deborah; WHELEHAN, Imelda (Ed.). Adaptations: from text to screen, screen to text. London/ New York: Routledge, 1999. p. 185-98.

CLÜVER, Claus. Estudos Interartes: conceitos, termos, objetivos. Literatura e Sociedade, São Paulo, USP-FFLCH, n. 2, p. 37-55, 1997.

GROENSTEEN, Thierry. Du $7^{\mathrm{e}}$ au $9^{\mathrm{e}}$ art: l'inventaire des singularités. CinémAction, hors série Cinéma et bande dessinée, Courbevoie, p. 16-28, 1990.

GRUSIN, Richard. DVDs, video games and the cinema of interactions. Ilha do Desterro, Florianópolis, n. 51, p. 69-91, 2006. Disponível em: $<$ http://www.diaadiaeducacao.pr.gov.br/diaadia/diadia/arquivos/File/conteudo/artigos_t eses/Ingles/grusin.pdf $>$. Acesso em: 7 mar. 2010.

JENKINS, Henry. Convergence culture: where old and new media collide. New York/London: NYU Press, 2006.

${ }^{16}$ LEFÈVRE. Incompatible visual ontologies? The problematic adaptation of drawn images, p. 2. 
LEFÈVRE, Pascal. Incompatible visual ontologies? The problematic adaptation of drawn images. In: GORDON, Ian; JANCOVICH, Mark; MCALLISTER, Matthew P. (Ed.). Film and comic books. Jackson: University Press of Mississippi, 2007. p. 1-12.

MILLER, Frank. Frank Miller's Sin city. $2^{\text {nd }}$ ed. Milwaukie: Dark Horse, 2005. v. 1: The hard goodbye.

MILLER, Frank. Frank Miller's Sin city. $2^{\text {nd }}$ ed. Milwaukie: Dark Horse, 2005. v. 3: The big fat kill.

MILLER, Frank. Frank Miller's Sin city. $2^{\text {nd }}$ ed. Milwaukie: Dark Horse, 2005. v. 4: That yellow bastard.

MOORE, Alan. Watchmen. Ilustrações: David Gibbons. New York: DC Comics, 1995.

RAJEWSKY, Irina O. Intermediality, intertextuality, and remediation. A literary perspective on intermediality. Intermédialités: histoire et théorie des arts, des lettres et des techniques/ Intermedialities: history and theory of the arts, literature and techniques, n. 6, p. 43-64, 2005. Disponível em: <http://cri.histart.umontreal.ca/cri/fr/intermedialites/p6/pdfs/p6_rajewsky_text.pdf >. Acesso em: 29 jul. 2010.

SIN CITY. Direção: Robert Rodriguez, Frank Miller. Intérpretes: Bruce Willis, Mickey Rourke, Clive Owen, Jessica Alba. Buena Vista, 2005.

WATCHMEN. Direção: Zack Snyder. Intérpretes: Jackie Earle Haley, Billy Crudup. Warner Bros, 2009. 